\title{
The Challenges Faced by the Parents of Autistic Children in Jordan
}

\author{
Emad Soud Nayef Ahmad
}

\begin{abstract}
The present study aimed to explore the challenges faced by the parents of autistic children in Jordan. The researcher adopted a descriptive analytical approach. He selected a purposive sample that consists from 8 mothers and 6 fathers who have autistic children. Those parents were selected from a private centre for autism in Amman, Jordan. They were contacted and interviewed via the phone. Their answers were analysed. It was found that the parents of autistic children in Jordan face financial, social, marital and psychological challenges. For instance, some respondents suggested that providing special education is costly. Some respondents suggested that it's difficult for them to engage in social events and make visits to their friends and relatives. Some respondents suffer from stress. Some respondents reported that their children were misdiagnosed. The researcher recommends conducting studies about the impact of having an autistic child on siblings in Jordan.
\end{abstract}

Keywords: Challenges, autistic children, autism, Jordan, parents

DOI: $10.7176 / \mathrm{JEP} / 11-28-09$

Publication date:October $31^{\text {st }} 2020$

\section{Introduction}

The number of autistic people have been increasing recently (Kuzminski et al., 2019). Therefore, it is very necessary to conduct research about autistic children and adults and explore the nature of this disorder (i.e. autism spectrum disorder (ASD). Autism is a neurodevelopmental disorder that is associated with social \& communication deficits. It is also associated with restricted and repetitive activities, interests and behaviours. It's associated with impaired joint attention, \& difficulties in understanding, establishing, and maintaining relationships. That applies to the relationship that the autistic child has with colleagues, siblings, co-workers and care givers (The American Psychiatric Association, 2013).

The language disorders \& learning and intellectual disabilities are considered common among autistic people. For instance, autistic people learn slowly and experience failure in producing language and comprehending it. They usually experience failure in comprehending and using the function of the language (e.g. irony). They fail in employing expressive gestures. They also fail in following someone's eye gaze (The American Psychiatric Association, 2013).

Autistic people have poor capability in determining which behaviours are considered appropriate. They have carry out disruptive behaviours and experience a lack of interest in interacting socially with others. They have poor imagination and adaptive skills. In fact, only minority of adults with autism can hold a job and live independently. Despite that, those adults are still socially naïve and vulnerable and suffer from difficulties in meeting daily life demands. They are prone to experiencing anxiety and depression (The American Psychiatric Association, 2013).

In other words, autism is a lifelong developmental disability that affects one in social, occupational, educational, interactive and behavioural areas (Begum and Mamin, 2019). It is difficult to diagnose the child with autism. That's because such disorder doesn't have any clear biological marker. Thus, making such diagnosis requires making a clinical evaluation. The latter evaluation includes: interviewing parents, making clinical observations and speech and language assessments. It requires using psychological tests. It includes analysing the child development-related data, and using an autism checklist. Despite such difficulty, autistic children are usually diagnosed with autism during the first three years of their lives (Bashir et al., 2014). After making such diagnosis, autistic children must receive special care and education by parents, schools management, teachers, therapists, caregivers and etc.. (Pandey, 2018).

Parents of autistic children have many responsibilities. For instance, they must teach their autistic children the way to communicate with others. They must develop their autistic children's basic life skills and protect them from danger. That shall improve the capability of those children to live independently in the future (Dyches et al 2004). In addition, those parents must ensure that the siblings of autistic children don't feel jealous nor have resentment. They must provide those siblings with information about autism in order to know how to take care of their autistic brothers/ sisters (Ferraioli and Harris, 2009).

Because the parents of autistic children have too many responsibilities, they usually suffer from too much stress. Such stress may be attributed to the lack of spousal, social and professional support (Gupta and Singhal, 2014). It may be attributed to suffering from many psychological, social, marital, physical and financial challenges that are difficult to handle (Omar et al., 2017). Such psychological challenges may include: the high risk of feeling guilty, helpless, and angry and experiencing self-blame and depression. Social challenges may include: suffering from social isolation due to the difficulty of making visits to family members and friends. They may include: 
having marital discord (Gupta and Singhal 2005). In fact, the divorce rate among the families having an autistic child is greater than the counterpart rate among the families that don't have an autistic children (Hartley et al., 2010).

The inappropriate public behaviours of autistic children may make their parents feel embarrassed. Those parents may face hostile or insensitive reactions from the public due to their children's behaviour (Bashir et al., 2014) In addition, they suffer from the stereotypes and the negative perceptions of the public towards their autistic children (Gray 1993). In the light of the aforementioned information, parents with autistic children must be provided with support by friends, relative and neighbours (Meral, and Cavkaytar, 2012). They must be provided with support groups to handle such challenges effectively (Jackson et al., 2018). In addition, there is a need to conduct studies for exploring the challenges faced by those parents in all countries, especially in developing countries. Hence, the researcher of the present study aimed to explore the challenges faced by the parents of autistic children in Jordan.

\section{Objectives}

The present study aimed to

-Identify the challenges faced by the parents of autistic children in Jordan

-Make suggestions for addressing the challenges faced by the parents of autistic children in Jordan.

\section{Questions}

The present study aimed to answer the following questions:

Q.1. What are the challenges faced by the parents of autistic children in Jordan?

Q.2. What suggestions could be made for addressing the challenges faced by the parents of autistic children in Jordan?

\section{Significance of the Study}

The present study is significant because it fills a gap in the relevant literature. For instance, there aren't many studies conducted about the challenges faced by the parents of autistic children in Jordan. The present study is significant because it provides decision makers at the Jordanian Ministry of Social Development with information about the challenges faced by the parents of autistic children in Jordan. Such information shall enable decision makers at the latter ministry to address such challenges and improve the living conditions of the parents of autistic children.

The present study is significant because it promotes awareness among the public about the challenges faced by parents of autistic children. Promoting such awareness shall contribute to fighting the stigma associated with autism. It shall make the public empathize with the parents of autistic children. In addition, exploring the experiences of those parents shall provide policy makers in Jordan with information about the kind of support that must be provided for the parents of disabled children in general and parents of autistic children in particular.

\section{Limits:}

Temporal limits: The present study was conducted during the period (October / 2019 - December / 2019).

Spatial limits: This study was conducted in a private centre for autism in Amman, Jordan.

Human limits: This study targets the parents of autistic children in Jordan.

\section{Definition of Terms}

-Autism (theoretical definition): It is a neurodevelopmental disorder that is associated with social \& communication deficits. It is also associated with restricted and repetitive activities, interests and behaviours. It's associated with impaired joint attention and difficulties in understanding, establishing, and maintaining relationships. That applies to the relationship of the autistic child with his/her colleagues, siblings, co-workers and care givers (The American Psychiatric Association, 2013).

-Autistic parents: (Operational definition): The parents in Jordan who have a child whose age is below 15 years and was diagnosed with autism.

Challenges (Operational definition): They refer to the challenges faced by the parents of autistic children in Jordan

\section{Theoretical Framework}

It has been suggested that the mothers of autistic children face much difficulty in achieving a successful career. That is because mothers have numerous childcare demands that must be met (Thyen et al., 1999). In addition, those mothers suffer from depression. Their depression may be attributed to the stigma that is associated with having an autistic child (Gray, 2002). Those mothers are at high risk of experiencing depression and anxiety (Hastings and Brown, 2002). As for the fathers of autistic children, they suffer from challenges too. For instance, they seek supressing their feelings about having an autistic child. Hence, they tend to express anger to express such supressed 
feelings (Gray, 2003).

It's suggested that the siblings of the autistic child are prone to experiencing emotional, psychological and behavioural problems. For instance, such siblings may feel that they are being treated in an unfair manner. They may feel that meeting their needs is considered secondary by their parents. They may feel resentment, because their parents dedicate much time and care for the autistic child. They may experience anger, embarrassment, and guilt, due to failure in meeting their high parental expectations. They may feel angry because too many household duties are assigned to them. Hence, it's challenging for the parents of autistic children to ensure that the siblings of autistic children don't have negative feelings. It is challenging for those parents to ensure that their autistic and normal children have good relationships with each other (Gupta and Singhal, 2005).

Having an autistic child shall negatively affect the relationships between the members of the same family because autistic children are time consuming (Knapp et al., 2009). Having an autistic child shall negatively affect the financial level of the family. It shall negatively affect the marital relationship and career of the spouses (Rao and Beidel, 2009). Having an autistic child shall make his/her siblings prone to experiencing problems with peers and feelings of loneliness (Ferraioli and Harris, 2010). Having an autistic child shall make his/her siblings prone to learning, social, cognitive, learning and linguistic difficulties. Hence, parents must ensure that that their normal children aren't neglected (Ben-Yizhak et al., 2011).

It's mentally and physically exhausting to raise up an autistic child. Hence, the prevalence of physical, and mental health problems among the parents of autistic children is greater than the counterpart prevalence among the parents who have children with another developmental disability (Karst, and Van Hecke, 2012). There are several challenges faced by the parents of autistic children. For instance, those parents suffer from the lack of services provided by the state. For instance, some states don't provide adequate assessment, therapeutic intervention, and diagnosis services. However, intensive, early and individualized interventional services must be provided to those children to develop them. The latter services should be provided because they have a significant impact on the development of autistic children. Hence, many parents seek providing therapy to their autistic children at home at their own expense (Grasu, 2015).

Parents of autistic children face educational challenges. In addition, acceptance of those children in inclusive schools is challenging and difficult. It's also very difficult to find inclusive schools that are well-prepared and have adequate resources for providing care and education to autistic children. Many parents experience stress about the rejection of the normal peers at school to interact with their autistic child and engage him/her in group games. Parents also worry about the future of those children. They worry about the idea of dying and having no one to take care of the child. The challenges of those parents include: the rejection of those children and the stigmatization associated with this disease. Such stigmatization makes the parents feel guilty, and shame and refrain from going to social events and visits. Parents may feel embarrassed because the behaviours of their autistic children may be perceived by others as signs of parental indulgence or parent's lack of education (Grasu, 2015).

The parents of autistic children face financial challenges. That is because many mothers may have to resign from their jobs to provide additional care to their autistic children. Those parents face financial challenges because the medical and therapeutic costs are high. In addition, in some cases, one of the spouses may abandon the family, because he/she rejects the autistic child. Such abandonment shall enforce an additional financial burden on the other spouse. Other challenges of autistic children may include: late diagnosis, and misdiagnosis. For instance, autistic children may be diagnosed incorrectly as being deaf or having delay in their mental development. Such mistakes hinder many parents from providing special care to their autistic children at an early age. Other challenges may include the lack of knowledge among specialists (Grasu, 2015).

It's suggested that the support groups shall enable those parents to handle much challenges. For instance, such groups enable those parent to fight against stress, frustration, and guilt, and highly qualified find service providers (e.g. doctors, therapists, and lawyers). They enable those parents to learn more about time and financial management due to suffering from problems in this regard (Jackson et al., 2018)

According to Begum and Mamin (2019), having an autistic child is associated with several marital, financial, professional and personal problems. For instance, having an autistic child changes the life style of the family. It reduces the family annual income. It requires dedicating much money for providing special educational and medical care to the autistic children. Hence, it is negatively associated with the financial status of the family. It's suggested that handling the challenges faced by the parents of autistic children requires providing those parents with training courses by professionals. Handling such challenges requires providing medical care for autistic children and engaging those parents in support groups (Begum and Mamin, 2019)

\section{Review of Empirical Studies}

Ludlow et al. (2012) aimed to explore the challenges faced by the parents of autistic children in Ghana. They conducted interviews with the members of the sample to collect data. The sample consists from 20 parents who have autistic children. It was found that such challenges include: the need to tolerate the judgments made by others, and the need to handle the challenging behaviours of autistic children. Such challenges include: the lack of support, 
and having to face family-related challenges.

Omar et al. (2017) aimed to explore the challenges faced by the mothers of autistic children in Egypt. Data was collected through interviewing 76 mothers who have autistic children. Socio-demographic data was collected too. It was found that such challenges include: psychological challenges. For instance, mothers experience sadness, anger, nervousness, stress and anhedonia. Such psychological challenges may be attributed to being uncertain about child's future, and health. The challenges faced by those mothers include: financial challenges because the costs of education and healthcare services are high (Omar et al., 2017).

The challenges faced by the mothers of autistic children include: physical challenges. For instance, those mothers have too many caregiving demands to be met. They keep waking up at night to take care of the autistic child. They also face social challenges. For instance, some mothers complained about how difficult it is to make social visits to relatives and doing recreational activities. That made many mothers feel socially isolated. Other social challenges include: the jealousy and sadness of the autistic child's siblings. That is because the autistic child is granted too much support. The challenges faced by the mothers of autistic children include: the unavailability of community services and lack of mothers' awareness about autism. They also include: having bad marital relationships, because the spouse is not willing to take care of the child nor have discussions about the autistic child-related issues (Omar et al., 2017).

Gobrial (2018) aimed to explore the challenges faced by the mothers of autistic children in Egypt. Data was collected through interviewing 14 mothers who have autistic children and live in Egypt. The ages of the children are within the range of 5-14 years. It was found that such challenges include: late diagnosis and misdiagnosis and lack of adequate knowledge about autism among professionals and mothers. Such challenges include: the lack of resources and rehabilitation, healthcare and social care services at public facilities. Such challenges include: rejection of autistic children at schools. They include: having financial burdens, because the interventional, speech therapy and special educational services and are costly. They include challenges related to emotional wellbeing and mental health problems (e.g. depression). Some parents experienced guilt because they think they may have did something that caused this disorder. Some parents felt frustrated due to having an undesired parenting experience (Gobrial, 2018)

The challenges faced by the mothers of autistic children include: having to make personal sacrifice, such as: having to quit a job because the day-care centres are expensive. Such personal sacrifice include: having to work additional hours or hold two jobs to pay for the expenses of their autistic children. The challenges faced by the mothers of autistic children include: social life-related challenges. For instance, parents avoid going in public due to feel embarrassed about their children's behaviour. They reported difficulty in attending social events and occasions. That made those mothers experience social isolation. Few mothers reported lack of spousal support. The challenges faced by the mothers of autistic children include: worrying about the future of the child, especially when getting old or die. They include: facing stigmatization and negative perceptions. Such negative perceptions include: considering the child's behaviour as signs of bad parenting. The respondents suggested that the extended family members showed empathy and support (Gobrial, 2018).

Agyekum (2018) aimed to explore the challenges faced by the parents of autistic children in Ghana. He collected data through making interviews with parents of autistic children. The sample consists from ten parents of autistic children. It was found that such challenges include: having financial burdens. For instance, the medical care provided for autistic children is costly. In addition, providing special education for autistic children in private institutions is costly. The challenges faced by those parents include: suffering from much stress due to having too many childcare duties. For instance, many parents don't have nannies nor family members who are willing to provide assistance in taking care of the child. Such challenges include difficulties in communicating with children which is considered stressful for those parents. That is because those children can't communicate verbally in an effective manner. Such challenges include stigmatizing the child. They include: the social rejection of autistic children. For instance, some people avoid interacting with those children.

Bakri et al. (2019) aimed to explore the challenges faced by the parents of autistic children in Malaysia. Data was collected from 52 parents. It was collected through using a questionnaire. It was found that those parents suffer from poor sense of competence, health problems, social isolation, depression, and stress, and have problems with the spouse. The severity of the disability affects the severity of the stress. The latter researchers recommend employing strategies to handle such stress.

\section{Methodology}

\subsection{Approach:}

The descriptive analytical approach was adopted.

\subsection{Population and Sample:}

The population is represented in all the parents of autistic children in Jordan. However, the criteria must apply to the members of the sample: 1)- Their autistic child must have been diagnosed with autism only and doesn't suffer 
from any other disorder. 2)- The age of the child must be below 15 years. 3)- The parent must be living in Jordan.

The researcher selected a purposive sample that consists from 8 mothers and 6 fathers who have autistic children. Those parents were selected from a private centre for autism in Amman, Jordan. They were contacted and interviewed via the phone. The phone numbers of those parents were obtained from the selected centre. The answers of the interviewees were analysed to reach results and suggest recommendations.

Table (1): Characteristics of the sample

\begin{tabular}{|l|l|l|l|}
\hline Variable & Category & Frequency & Percentage \\
\hline \multirow{4}{*}{ Gender } & Male & 6 & 42.857 \\
\cline { 2 - 4 } & Female & 8 & 57.1428 \\
\hline \multirow{4}{*}{ Age } & Less than 30 years & 3 & 21.428 \\
\cline { 2 - 4 } & 30- 40 years & 6 & 42.857 \\
\cline { 2 - 4 } & More than 40 years & 5 & 35.7142 \\
\hline
\end{tabular}

$\mathrm{N}=14$

$57.14 \%$ of the respondents are females and $42.85 \%$ of the respondents are males. $42.85 \%$ of the respondents' ages are within the range of $30-40$ years. $35.71 \%$ of the respondents are older than 40 years. $21.42 \%$ of the respondents' ages are less than 30 years.

\subsection{Instrument}

The researcher collected data through making interviews with 8 mothers and 6 fathers who have autistic children. He drafted the questions of the interviews after reviewing several studies, such as: Omar et al. (2017) Meral and Cavkaytar (2012) and Grasu (2015). The interview consists from the following questions:

Q.1. What are the financial challenges you face as a parent of an autistic child?

Q.2 What are the social challenges you face as a parent of an autistic child?

Q.3. What are the psychological challenges you face as a parent of an autistic child?

Q.4. Are there are other challenges that you face as a parent of an autistic child?

Q.5. Do you receive adequate support from your: spouse, relatives, friends and the government? (This is a yes/no questions)

Q.6. What suggestions could be made for addressing the challenges faced by the parents of autistic children in Jordan?

\subsection{Validity of the Instrument}

The questions of the interview were passed to two faculty members in a Jordanian university. Those faculty members are specialist in special education were asked to assess the capability of those questions to meet the intended goals. They suggested that the questions are clear and capable of meeting the goals of the study.

\subsection{Statistical analysis:}

The researcher used descriptive statistical methods (i.e. percentages and frequencies). To classify percentages, the following criteria were adopted:

$0 \%-33.33 \%$ : Low:

$33.34 \%-66.66 \%$ : Moderate

$66.67 \%-100 \%$ : High

The interval between each criterion is calculated based on the equation below: (Razzak et al, 2019)

(The maximum value - the minimum value) / The number of the required criteria $=(100-0) / 3=33.333$

\section{Discussion and Results}

10.1. Discussion and Results Related to Question One:

Q.1. What are the challenges faced by the parents of autistic children in Jordan?

To explore the challenges faced by the parents of autistic children in Jordan, the answers of the sampled parents were analysed and presented below. Each parent was given a code number by the researcher. The challenges that were faced by the respondents are listed below

[1] Financial challenges:

10 respondents suggested that providing their autistic children with good special education is costly. The latter result is consistent with the results concluded by Begum and Mamin (2019). 8 respondents suggested that the providing their children with therapy and medications is costly. The latter result is consistent with the results concluded by Grasu (2015). 4 parents suggested that they had to pay much money to get the right diagnosis. 5 mothers suggested that they had to quit their jobs to take care of their autistic children which negatively affected the family income. Hence, having an autistic child shall make it difficult for the mother to work. The latter result is consistent with the results concluded by Gobrial (2018). For instance, a mother said: 'I had to quit my job, because my child is in need for additional care. I must take care of my child"'. 


\section{[2] Social challenges:}

11 respondents suggested that it's difficult for them to make visits to relatives and friends and engage in social occasions and celebrations. Some of those parents suggested that it's difficult to find a trusted nanny to take care of the child while going to social occasions and events. Some of those parents suggested that this is difficult because they feel embarrassed about their children's behaviour in social occasions and visits. The latter result is consistent with the results concluded by Gobrial (2018). For instance, a mother said: 'I can't attend many weddings and visit my friends like I used to. I can't find a trusted nanny to take care of my child to take care of my child while I am away'.

7 respondents suggested that they face difficulty in doing leisure or recreational activities. The latter result is consistent with the results concluded by Omar et al. (2017). For instance, a father said: 'It has become difficult for me to spend much hours at the gym like I used to. That's because I have to dedicate more time in assisting my wife in taking care of the child'.

4 parents suggested that it's challenging to make sure that the autistic child and his/her siblings have good relationship with each other. That's because those siblings may feel jealousy or treated unfairly. The latter result is consistent with the results concluded by Gupta and Singhal (2005). For instance, a mother said: 'I have to provide additional care to my autistic child without making his brothers and sisters feel jealous or mad'.

[3] Psychological challenges:

12 respondents suggested that they suffer from stress. Some of those parents attributed their stress to having many childcare duties. Some of those parents attributed their stress to having financial burdens. Others attributed their stress to the difficulty in communicating with the child. The latter result is consistent with the results concluded by Jackson et al. (2018). For instance, a father said: 'I am have much stress, because I must meet the financial demands of my autistic child'. A mother said: 'I am suffering from much stress, because I have numerous duties to do, such as: cleaning the house, helping my other children in their homework, taking my autistic child to the therapist and etc.. I have to assist my autistic child in doing everything'.

4 parents suggested that they suffer from anxiety. One of those parents attributed her anxiety to the rejection of her husband for the autistic child at the beginning. She said: ' After the diagnosis of my autistic child, my spouse rejected the idea of having an autistic child. He used to spend many hours with his friends at the café. However, later on, he accepted our autistic child. He has been showing much support for me and my child'. The latter result is consistent with the results concluded by Hastings and Brown (2002). One of the sampled parent suggested that she used to suffer from depression. She attributed that to the rejection of her child by his peers and the way people treat her child. The latter result is consistent with the results concluded by Gray (2002).

[4] Marital challenges:

4 parents suggested that they have/ or used to have marital problems due to having an autistic child. One of the parents attributed those problems to the financial challenges. He said: ' $M y$ wife and I used to fight a lot due to issues related to my autistic child', The latter result is consistent with the results concluded by Hartley et al. (2010).

[5] Other challenges:

5 parents suggested that their child was misdiagnosed at the beginning. That may be attributed to the lack of knowledge among specialists in Jordan. The latter result is consistent with the result concluded by Gobrial (2018). For instance, a father suggested: ' I had to visit three specialists to get the right diagnosis', 6 parents suggested that they found difficulty in communicating with their child. Such difficulty hinders them from identifying the needs and demands of their child. For instance, a mother said: 'Sometime, my child cries and I couldn't know why',.

[6] Adequacy of the support received from the spouse, relatives, friends and the government Table (2): The adequacy of the support received from the spouse, relatives, friends and the government

\begin{tabular}{|l|l|l|l|l|}
\hline Variable & Category & Frequency & Percentage\% & Level \\
\hline Do you receive adequate support from your spouse? & Yes & 12 & 85.71 & High \\
\cline { 2 - 5 } & No & 2 & 14.28 & Low \\
\hline $\begin{array}{l}\text { Do you receive adequate support from your } \\
\text { relatives? }\end{array}$ & Yes & 13 & 92.85 & High \\
\cline { 2 - 5 } & No & 1 & 7.14 & Low \\
\hline Do you receive adequate support from your friends? & Yes & 11 & 78.57 & High \\
\cline { 2 - 5 } & No & 3 & 21.42 & Low \\
\hline $\begin{array}{l}\text { Do you receive adequate support from the } \\
\text { government? }\end{array}$ & Yes & 4 & 28.57 & Low \\
\cline { 2 - 5 } & No & 10 & 71.42 & High \\
\hline
\end{tabular}

$85.71 \%$ of the respondents receive spousal support in raising up the autistic child. The latter result may be 
attributed to having much awareness about the support needed for raising an autistic child. It indicates that the sampled parents have much patience. In this regard, a parent suggested: ' My husband helps me in doing the daily household chores, like washing the dishes'.

It was found that $92.85 \%$ of the respondents receive adequate support from their relatives. The latter result may be attributed to the nature of the relationships between relatives in Western societies in general and the Jordanian society in particular. In this regard, a parent suggested: 'I have many relatives who willing to assist me at any time,"

$78.57 \%$ of the respondents receive adequate support from their friends. The latter result may be attributed to having friends who are cooperative. A parent suggested: "All my friends are supportive". 71.42\% of the respondents don't receive adequate support from their government. The latter result is attributed to the fact that the Jordanian government has poor resources. Having poor resources shall hinder the government from providing much support to the parents of autistic children or children with other disability. A parent suggested: ' $M y$ child should be provided with full coverage medical insurance",.

10.2. Discussion and Results Related to Question Two:

Q.2. What suggestions could be made for addressing the challenges faced by the parents of autistic children in Jordan?

[1] Creating support groups

10 parents suggested that centres of autism must create support groups for the parents of autistic children. Such groups must include professionals who are capable of providing social support.

[2] Providing support by the Jordanian Ministry of Social Development:

3 parents recommended dedicating funds by the Jordanian Ministry of Social Development for supporting the poor families who have autistic children.

[3] Providing medical insurance by the government:

5 parents suggested providing full coverage medical insurance by the government for autistic children. Such insurance shall enable those children to enjoy good health.

\section{[4] Providing professionals and doctors with training courses about autism}

That was suggested by 3 parents in order to get the right diagnosis in early life. Providing such training courses shall enable professionals and doctors to provide effective rehabilitate services for children.

\section{Conclusion}

It was found that the parents of autistic children in Jordan face financial, social, marital, psychological and other challenges. In terms of the financial challenges, the costs of providing special education and medication are high. In addition, several mothers were forced to quit their jobs to provide care to their children. That reduced that monthly income of the family. In terms of the social challenges, it's difficult for parents to make social visits. Parents feel embarrassed about their children's behaviours. It's difficult for those parents to do leisure activities. That is because providing care to autistic children is time consuming.

In terms of the marital challenges, parents of autistic children may suffer from marital problems. That is because raising up an autistic child is something challenging and requires having cooperation between the spouses. In terms of the psychological challenges, parents of autistic children suffer from much stress. Such stress may be attributed to having many childcare-related duties. Those parents are prone to anxiety and depression which may be attributed to the social rejection of those children in society.

There are other challenges facing the parents of autistic children in Jordan. For instance, some autistic children were misdiagnosed. The misdiagnosis hinders parents from providing early interventional services to their children. It was found that the spouse, relatives, and friends of the respondents are supportive. However, it was found that the Jordanian government doesn't provide adequate support to respondents. Hence, the Jordanian government must develop policies for improving the diagnosis and rehabilitation services provided for autistic children at public hospitals and facilities.

\section{Recommendations}

The researcher recommends the following:

Developing policies and making decisions in Jordan for addressing the challenges faced by the parents of autistic children

Increasing the amount of funds dedicated by the government for supporting the poor families who have autistic children

- Developing several public centres for autistic children that aim at providing free special educational services for autistic children. Highly qualified professionals must be recruited in such centres Establishing more public clinics that are specialized in providing medical and rehabilitation services for autistic children for free. 


\section{Suggestions for Researchers}

The researcher recommends the following:

Conducting studies about the impact of having an autistic child on his/her siblings in Jordan.

Conducting studies about the relationship between the challenges of the parents of autistic children from one hand and other variables from another hand. Such variables may include: the parent's marital status, income, gender, academic qualification, employment status and etc,,,.

Conducting studies about the challenges faced by the special education teachers who teach autistic children in Jordan.

\section{References}

Agyekum, H. (2018) Challenges and coping strategies for parents with autistic children. Journal of Mental Disorders and Treatment, 3(4): 166. doi:10.4172/2471-271X.1000166

American Psychiatric Association. (2013). Diagnostic and statistical manual of mental disorders (5th ed.). Arlington, VA: Author

Bakri, A.; Rosli, N.; Mohd, K.; Othman, F.; and Kasim, T. (2019). Dimensions of stress in parents of children with autistic spectrum disorder. Makara Journal of Health Research (MJHR), 23(3), p. 127-131.

Bashir A, Bashir U, Lone A, Ahmad Z. (2014). Challenges faced by families of autistic children. International Journal of Interdisciplinary Research and Innovations. 2(1):64-68.

Begum R, and Mamin F. (2019). Impact of autism spectrum disorder on family. Autism-Open Access 9(4). Doi: 10.35248/2165-7890.19.09.244. Retrieved from:

https://www.longdom.org/open-access/impact-of-autism-spectrum-disorder-on-family-44919.html

Ben-Yizhak N, Yirmiya N, Seidman I, Alon R, Lord C, Sigman M. Pragmatic language and school related linguistic abilities in siblings of children with autism. Journal of Autism and Developmental. 41(6), p 750-760

Dyches, T.; Wilder, L.; Sudweek, R.; Obiokor, F.; and Algozzine, B. (2004). Multicultural issues in autism. Journal of Autism and Developmental Disorders, 34(2).

Ferraioli, S.; and Harris, S. (2010). Social Work in mental health: The impact of autism on siblings. Journal of Family Studies. 16(2), p.179-180.

Ferraioli, S.; and Harris, S. (2009). The impact of autism on siblings. Social Work in Mental Health. 8(1). p. 4153

Gobrial, E. (2018). The lived experiences of mothers of children with the autism spectrum disorders in Egypt. Social Sciences, MDPI, Open Access Journal. Vol. 7(8), pages 1-11, August.

Grasu, M. (2015). Challenges in families with a child with autism spectrum disorder. Bulletin of the TransilvaniaUniversity of Braşov: Series VII: Social Sciences, 8 (57)

Gray, D. (1993).Perceptions of Stigma: The parents of autistic children. Sociology of Health and Illness, 15(1).

Gray, D. (2003). Gender and coping: The parents of children with high functioning autism. Social Sciences and Medicine. 56(3):631-642.

Gray, D. (2002). Everybody just freezes-Everybody is just embarrassed: Felt and enacted stigma among parents of children with high functioning autism. Sociology of Health \& Illness, 24(6): p. 734-749.

Hartley, S.; Barker, E.; Seltzer, M.; Floyd, F.; Greenberg, J.; and Orsmond G. (2010). The relative risk and timing of divorce in families of children with an autism spectrum disorder. Journal of Family Psychology. 24(4).

Hastings R.; and Brown, T. (2002). Behavior problems of children with autism, parental self-efficacy and mental health. American Journal of Mental Retardation. 107(3):222-232.

Jackson, J. B., Steward, S., Roper, S. O., \& Muruthi, B. A. (2018). Support group value and design for parents of children with severe or profound intellectual and developmental disabilities. Journal of autism and developmental disorders, 48(12), 4207-4221. https://doi.org/10.1007/s10803-018-3665-z

Karst, J. and Van Hecke, A. (2012). Parent and family impact of autism spectrum disorders: A review and proposed model for intervention evaluation. Clinical Child and Family Psychology Review, 15(3):247-277

Knapp M, Romeo R, Beecham J. (2009). Economic cost of autism in the UK. Autism. 13(3). p. 317-336.

Kuzminski R, Netto J, Wilson J, Falkmer T, Chamberlain A, Falkmer M (2019) Linking knowledge and attitudes: Determining neurotypical knowledge about and attitudes towards autism. PLOS ONE, 14(7). Retrieved from: https://doi.org/10.1371/journal.pone.0220197

Ludlow, A.; Skelly, C.; and Rohleder, P. (2012). Challenges faced by parents of children diagnosed with autism spectrum disorder. Journal of Health Psychology. 17(5), p. 702-711

Meral, B. and Cavkaytar, A. (2012). A study on social support perception of parents who have children with autism. International Journal on New Trends in Education and Their Implications, 3(3)

Omar, T.; Ahmed, W.; and Basiouny, N. (2017). Challenges and adjustments of mothers having children with autism. Alexandria Journal of Paediatrics. 30(3). p. 120-129

Pandey, S., \& Sharma, C. (2018). Perceived burden in caregivers of children with autism spectrum disorder in Kathmandu Valley. Journal of Nepal Health Research Council, 16(2), 184-189. Retrieved from 
https://www.nepjol.info/index.php/JNHRC/article/view/20308

Rao P.; and Beidel, D. (2009). The impact of children with high-functioning autism on parental stress, sibling adjustment and family functioning. Behavior Modification. 33(4):437-451.

Razzak, L.; Mawdieh, R.; Karam, A.; Aljaafreh, A.; and Al-Azzaw, M. (2019). Determining the challenges faced by Syrian refugees students at Jordanian camps according to their perspective: A case of universities role to supporting. Modern Applied Science. 13 (8).

Thyen, U.; Kuhlthau, K.; and Perrin, J. (1999). Employment, child care, and mental health of mothers caring for children assisted by technology. Paediatrics. 103(6):p. 1235-1242 